\title{
ДЕТЕРМИНАНТЫ СОЗДАНИЯ И РАЗВИТИЯ САМЫХ БЫСТРОРАСТУЩИХ ТЕХНОЛОГИЧЕСКИХ КОМПАНИЙ "
}

\author{
(C) 2020 Дзюбенко Ирина Борисовна
}

научный сотрудник Отдела управления промышленными предприятиями ИЭОПП СО РАН Института Экономики и Организации Промышленного Производства СО РАН, Россия, Новосибирск

E-mail: Konsult-I@yandex.ru

ORCID https://orcid.org/0000-0002-7748-5486/

Статья посвящена выявлению факторов создания, присутствия и роста самых быстрорастущих технологических компаний, признанных ключевым фактором экономического роста и структурных изменений, в разных странах и регионах. Для достижения этой цели данные 29 стран Европы и Ближнего Востока подвергнуты нескольким методам многомерного анализа, в частности корреляционному и кластерному анализу. Исследована взаимосвязь распространения и развития быстрорастущих технологических компаний с уровнем и динамикой богатства страны и благосостояния населения, внутренними затратами на НИОКР. Проведен кластерный анализ, в результате которого выявлены характеристики предпринимательской экосистемы, объясняющие различное присутствие и рост таких компаний в разных странах. Результаты анализа могут быть использованы в процессах разработки и реализации мер поддержки быстрорастущих компаний.

Ключевые слова: Быстрорастущие компании, высокотехнологичный бизнес, экспоненциальные организации, технологические экосистемы, предпринимательские экосистемы, институциональные условия, экономический рост.

\section{Введение}

Ожидание экономического роста, повышения производительности труда и создания рабочих мест является причиной пристального внимания и целью государственной политики на различных уровнях во всех странах. Быстрорастущие компании наиболее представлены в высокотехнологичных отраслях экономики, особенно в секторе наукоемких услуг. Они повсеместно распространены, но не равномерно распределены в разных странах. По данным Евростат, в период 2014-2017 гг. количество быстрорастущих компаний в странах ЕС увеличилось на 30\% (что намного превышает 9\% темп роста числа всех активных фирм в бизнесэкономике ЕС), и их доля составила около $11 \%$ предприятий в деловой экономике (European Commission, 2019). Это демонстрирует важность быстрорастущих компаний в динамике бизнеса европейских стран.

Несмотря на актуальность исследуемой проблемы и повышенное внимание к ней, сохраняется неравенство в отношении способности инициировать создание быстрорастущих ком- паний и управлять ими. Изменчивость условий, в которых работают компании, их макроэкономической и институциональной среды, предпринимательской экосистемы в целом подразумевает, что благоприятная для быстрорастущих компаний политика должна быть адаптирована к специфике государства (Bosma, Stam, 2012) Это делает актуальным межстрановой анализ быстрорастущих компаний, который учитывает экономические условия, институциональную среду, другие характеристики предпринимательской экосистемы. Оценка макроэкономической и институциональной среды, инновационной экосистемы, в которой функционируют быстрорастущие компании, может помочь понять детерминанты их создания и развития, выявление которых является целью данного исследования.

Исследование сосредоточено на самых быстрорастущих высокотехнологичных компаниях, демонстрирующих чрезвычайно высокие темпы роста - гиперрост (Sloan, 2020). Это гораздо меньшее количество компаний, связанных с высокими рисками, создающих и использующих

\footnotetext{
* Источник финансирования: Статья подготовлена по плану НИР ИЭОПП СО РАН в рамках проекта ХІ.172.1.3 (№ AAAA-A17-117022250130-8) «Теория и методология стратегического управления развитием высокотехнологичного бизнеса как базиса новой индустриализации».
} 
новые экспоненциальные технологии и новые непроверенные бизнес-модели, менее всего изучено в экономической литературе. Рост таких компаний имеет рециклическую положительную динамику и не зависит напрямую от размера экономики и темпов экономического роста. Напротив, наблюдается взаимосвязь динамики роста экономики страны с концентрацией и динамикой роста быстрорастущих высокотехнологичных компаний. Недостаточное развитие (как пространственное, так и интенсивное) этих компаний свидетельствует о недостаточном развитии региональной экономики (Дзюбенко, Дзюбенко, 2018). Поэтому анализ таких компаний, представляет большой научный и практический интерес.

В результате исследования выявлено, что условия функционирования самых быстрорастущих высокотехнологичных компаний существенно отличаются в разных странах и регионах. Масштаб экономики страны, емкость внутреннего рынка, объем внутренних затрат на НИОКР не являются определяющими факторами количества и региональной концентрации самых быстрорастущих высокотехнологических компаний. Присутствие и развитие высокотехнологичных быстрорастущих компаний обусловлено в большей степени спецификой деловой среды, институтов, предпринимательской экосистемы в целом. Самые быстрорастущие технологические компании более распространены в странах с высоким уровнем благосостояния населения, эффективными институтами, развитой инфраструктурой, устойчивыми инновационными экосистемами, чем в странах, конкурентоспособных по уровню ВВП. Такие компании быстрее растут в странах с высокими темпами экономического роста, но эта взаимосвязь двусторонняя: более высокий рост ВВП ведет к большему количеству возможностей роста компаний и наоборот, более высокие темпы роста компаний способствуют более высокому росту ВВП (Teruel Carrizosa, De Wit, 2011).

\section{Обзор литературы}

Понятие «быстрорастущая компания» (БРК) или «газель» (high-growth firm (HGF), gazelle) фирма, отличающаяся высокой скоростью и одновременно устойчивостью роста - было введено Дэвидом Берчем в 80-90-е гг. XX века (Birch, 1979, Birch, Medoff, 1994). Авторы более поздних исследований подтвердили выводы Д.Берча о том, что динамичность быстрорастущих компаний предопределяет их значительный вклад в развитие национальной экономики (Autio, Hölzl, 2008, Coad et al., 2014, Halla, Harasztosi, 2019, Ferrando et al., 2019, Brown et al., 2017). Высокая экономическая значимость БРК напрямую связана с их ролью в качестве создателей рабочих мест (Autio, Hölzl, 2008, Coad et al., 2014, Halla, Harasztosi, 2019), даже если это воздействие с точки зрения чистых эффектов или качества работы и местоположения не является прямым (Brown et al., 2017). Так, в период 2003-2016 гг. на долю быстрорастущих компаний пришлось 44\% общего числа новых рабочих мест, а также 29\% роста оборота всех фирм в странах ЕС. При этом большая доля чистого роста занятости - 53\% приходилась на долю инновационных БРК (в период 2014-2015 гг. этот показатель составил 90\%) (Ferrando et al., 2019). Кроме того, БРК создают важные побочные и демонстрационные эффекты, используя производительность сектора или региона, в котором они расположены (Monteiro, 2019). Еще одной причиной экономической значимости БРК является их активное воздействие на предпринимательскую экосистему (Mason, Harrison, 2006) В этом контексте изучение высокотехнологичных БРК может способствовать пониманию того, как и почему компании растут, какое влияние на экономическое развитие страны оказывают создаваемые ими технологические экосистемы.

Несмотря на общепризнанную БРК, до сих пор не существует их общепринятого определения или метода измерения и в литературе нет единого понимания, какие компании являются быстрорастущими. Широкое распространение получило определение, предлагаемое ОЭСР: «быстрорастущими являются предприятия со средним годовым ростом численности работников более $20 \%$ в год в течение трехлетнего периода и с десятью или более работниками в начале периода наблюдения» (OECD, 2008), которое все чаще понимается как синоним термина «масштабирование». Евростат определяет БРК как предприятия со средним годовым ростом численности работников более $10 \%$ в год в течение трехлетнего периода (European Commission, 2013). Существует также множество определений БРК, каждое из которых соответствует уникальной выборке компаний в зависимости от исследуемых показателей (численности занятых, выручки, прибыли, доли рынка и др.), из- 
мерения роста (абсолютные или относительные показатели), анализируемого периода и типа роста (органический или путем слияний и поглощений) (Daunfeldt et al., 2010). Структура и результаты анализа зависят от способа идентификации БРК (Davidsson et al., 2010), эмпирические исследования быстрорастущих компаний характеризуются различиями в определении и методологии, что существенно затрудняет анализ и сопоставление имеющихся результатов, особенно на межстрановом уровне.

В своем исследовании мы ориентируемся на рост доходов, а не на рост занятости или прибыли компании. Преимущество использования дохода (выручки) в качестве показателя роста заключается в том, что он измеряет как расширение масштаба деятельности, так и повышение эффективности (Achi et al., 1995). Мы фокусируемся на конкретном типе быстрорастущих компаний - самых быстрорастущих технологических компаниях, демонстрирующих сенсационный рост (Lia et al.,2016), имеющий экспоненциальный характер (Исмаил и др., 2017, Дзюбенко, 2018 a).

Такие компании в экономической литературе получили названия «Тигры» (Tigers) (Achi et al., 1995), «Звездные фирмы» (Star Firms) (Ayyagari et al.,2018), «Экспоненциальные организации» (Exponential Organizations) (Исмаил и др., 2017). Это гораздо меньшее количество компаний, связанных с высокими рисками, создающих и использующих новые экспоненциальные технологии и новые непроверенные бизнесмодели (Дзюбенко, Дзюбенко, 2018, Дзюбенко, 2020), менее всего изучено в экономической литературе. Из технологических быстрорастущих компаний вырастают Суперзвёздные фирмы (Superstar Firms) (Autor et al., 2020), Супергазели (Ács, 2015), в некоторых исследованиях называемые также «Большими гориллами» (Big gorillas) (Owen, 2004) и «Газиллами» (Gazillas) Ferrantino et al., 2012), а также Единороги (Unicorns) (Lee A., 2013, Simon 2016). Количество компаний Суперзвёзд и Единорогов в стране может служить показателем качества макроэкономической среды, развития институтов и того, насколько благоприятны условия для создания успешных масштабных проектов (Aldrich, Ruef (2018). История единорогов проливает свет на некоторые слабые стороны предпринимательских экосистем (Duruflé et al., 2018).

Наши предыдущие исследования показали, что самые быстрорастущие технологиче- ские компании активно создают собственные бизнес-платформы, что позволяет им обслуживать практически неограниченное количество прямых связей с партнерами и клиентами. Платформы становятся плодородной почвой создания и развития технологических и бизнесэкосистем, основанных на коллективных методах производства и потребления, которые размывают границы между цепочкой поставок, исполнителями, партнерами, клиентами и широкими массами (Маркова, Трапезников, 2016). «Технологические экосистемы создают среду и отношения, в которых высокотехнологичные компании быстрее растут и развиваются. Расширение технологических рамок позволяет компаниям объединить ресурсы и усилия, способствует экспоненциальным инновациям и усиливает влияние на эффективность затрат. Технологии, инновации и внешняя среда образуют предпринимательскую экосистему, одновременно подверженную влиянию высокотехнологичных компаний и оказывающую влияние на их рост» (Дзюбенко, 2018b).

Концепция предпринимательской экосистемы подчеркивает сложное взаимодействие между различными факторами окружающей среды и предпринимательской деятельностью в создании экономической динамики (Bruns et al., 2017). Многочисленные факторы (детерминанты) формируют предпринимательские экосистемы и оказывают влияние на создание и развитие быстрорастущих компаний (Stam, Spige, 2016,. Coad., Srhoj S., 2020). Учитывая это, ниже сосредоточимся на детерминантах, представляющих для нас наибольший интерес.

Предыдущие исследования показали, что БРК являются гетерогенной группой (Delmar et al., 2003) и их трудно предсказать, хотя существуют некоторые эмпирические закономерности. Например, установлено, что быстрорастущие компании часто моложе и меньше, они встречаются практически во всех отраслях (Henrekson, Johansson, 2010, Lopez-Garcia, Puente, 2012, Mason, Brown2013), особенно в некоторых секторах услуг (Schreye, 2000), и более распространены в высокотехнологичных секторах (Delmar et al., 2003, Hölzl, 2009). Отраслевая динамика оказывает существенное влияние на рост и конкурентоспособность компаний (Mason, 2020). Johnson J., Baldwin J. (1997) обнаружена тесная связь между динамикой роста внутри сектора и темпами роста фирм: «темпы роста фирм в растущих секторах выше, чем у фирм в стагниру- 
ющих или сокращающихся секторах. Молодые и растущие рынки, как правило, характеризуются низкими барьерами для входа и, следовательно, высокими показателями выхода».

Присутствие БРК особенно характерно для секторов с высоким уровнем человеческого капитала (Delmar et al., 2003). Интенсивность человеческого капитала оказывает положительное влияние на конкурентоспособность и рост компаний (Acs et al.,2007, Geroski et al.,2010)- чем выше уровень человеческого капитала, тем выше вероятность их быстрого роста (Almus, 2002). Поэтому уровень образования, профессиональные знания и способности, мотивация играют определенную роль в успехе БРК (Acs et al.,2007). На рост высокотехнологичных компаний существенно влияют уровень технологического развития и специализации региона (Audretsch, Dohse, 2007, Юсупова, Халимова, 2017). Как справедливо отмечают Земцов, Чернов (2019), «высокий уровень технологического развития региона упрощает трансферт технологий, служит показателем наличия источника новых знаний».

БРК в целом имеют тенденцию быть инновационными (Coad et al.,2014, Coad, Rao, 2008). В анализе связи между инновациями и ростом фирм актуален региональный аспект, поскольку на инновации сильно влияет структура экономической деятельности, которая широко варьируется в разных странах. Более высокая отраслевая концентрация в стране или регионе способствует распространению знаний между фирмами. Аналогичное воздействие оказывают технологическая плотность, географическая концентрация и кластеризация (Acs et al.,2007). Концентрация человеческого капитала компаний позволяет им активно расти за счет более низких издержек на привлечение квалифицированных работников. Положительное влияние на рост занятости, а также на быстрый рост выручки можно ожидать от партнерских отношений. Тесные связи с внешними фирмами, сотрудничество с научными учреждениями могут предоставить новые технологии, ноу-хау или капитал, а также сети с клиентами или поставщиками (Johnson, Baldwin, 1997) Важную роль в развитии БРК играют инфраструктура, сетевые эффекты (Coad, Rao, 2008), доступность и эффективность рынков ресурсов (труда, капитала и технологий) и товаров и услуг) (Davidsson et al.,2010). Развитию БРК способствует доступность венчурного капитала, который чаще используется высокотехнологичными БРК, чем другими фирмами.
Также важны международная торговля / глобальные цепочки создания стоимости (Coad et al.,2014).

Государственное регулирование и политика имеют первостепенное значение для роста компаний (Harabi, 2005). Более высокое нормативное и налоговое бремя для предприятий, превышающих определенные пороговые значения размера, может быть сдерживающим фактором роста компаний или привести к «расщепленному» росту (созданию новых спин-офф фирм) (Li, 2005). Качество институтов, уровень коррупции, степень доверия к политикам, бремя государственного регулирования влияют на создание и развитие БРК. Страны с меньшей бюрократией и более последовательными политическими режимами, создают больше высокотехнологичных фирм (Lopez-Garcia, Puente, 2012). О наличии предпринимательской экосистемы можно судить по тому, как она преобразует доступные на местном уровне предпринимательские таланты в деятельность и, в конечном итоге, в экономический рост (Bruns et al.,(2017).

\section{Данные и методология}

Методологической основой исследования являются общая теория экономического роста, системный анализ. В эмпирической части исследования использован широкий набор показателей, характеризующих макроэкономическую и институциональную среду, и другие рамочные условия функционирования быстрорастущих высокотехнологичных компаний. С помощью методов прикладной статистики и кластерного анализа исследованы различия в создании, присутствии и развитии высокотехнологичных БРК в разных странах. Для проведения расчетов, обработки и оценки используемой в работе информации применялись прикладные программные продукты Excel, IBM SPSS Statistica.

В эмпирической части исследования использованы данные о количестве и темпах роста компаний-победителей рейтинга Deloitte Touche Tohmatsu «Technology Fast 500 тм EMEA Ranking» 2016 г., охватывающего наибольшее число стран (Deloitte, 2016), а также информация с сайтов компаний. Участниками рейтинга являются технологические компании, которые: продемонстрировавшие самые высокие темпы роста доходов в течение последних четырех лет; находятся в бизнесе не менее четырех лет; имеют штаб-квартиру в странах региона ЕMEА и минимальный годовой доход в размере 80 тыс. 
евро в течение последних 4-х лет, а также собственные технологические разработки, доля от продаж которых в операционном доходе составляет не менее $50 \%$. В последние годы рейтинг Deloitte ориентирован на технологические экосистемы.

Результаты и их обсуждение

Самые быстрорастущие технологические компании работают в развивающихся секторах высокотехнологичного бизнеса - информационно-коммуникационных технологий, программного и аппаратного обеспечения, медикобиологических наук, чистых технологий (Рис. 1). Большая часть компаний-победителей рейтинга $(54,2 \%)$ сосредоточена в секторе программного обеспечения. Эти компании продемонстрировали относительно низкий средний рост выручки $-362 \%$ (Табл. 1$)$.

Быстрее всех росли компании сектора аппаратного обеспечения (962\%), доля которых в рейтинге составила менее $10 \%$. Сектор медиа занял вторую позицию по числу компаний и темпам их роста. Доля компаний этого сектора (14\%) в полтора раза больше сектора аппаратного обеспечения, но показатели роста, напротив, в полтора раза ниже. БРК сферы коммуникаций заняли третью позицию по количеству (их доля 12,2\%) и последнюю по темпам роста (345\%). 20 компаний сектора медико-биологических наук (5,8\% всех победителей рейтинга) увеличили

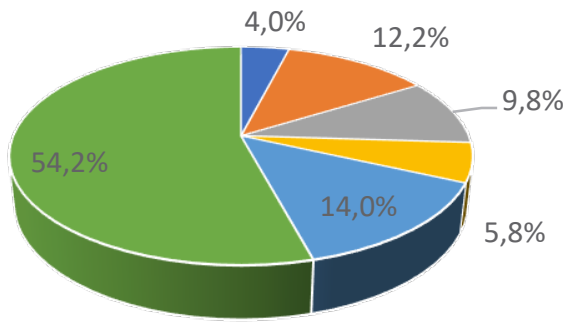

$$
\begin{aligned}
& \text { - Чистые технологии } \\
& \text { - Коммуникации } \\
& \text { - Аппаратное обеспечение } \\
& \text { - Медико-биологические науки } \\
& \text { - Медиа } \\
& \text { - Программное обеспечение }
\end{aligned}
$$

Puc. 1. Секторальная стуктура Technology Fast 500 тм EMEA Ranking 2016 Источник: составлен автором по данным Deloitte (2016)

Таблица 1. Количество компаний и показатели роста по секторам

\begin{tabular}{|l|c|c|}
\hline \multicolumn{1}{|c|}{ Сектор } & Количество компаний & Средний рост, \% \\
\hline Чистые технологии & 20 & 371 \\
\hline Коммуникации & 61 & 962 \\
\hline Аппаратное обеспечение & 49 & 347 \\
\hline Медико-биологические науки & 29 & 644 \\
\hline Медиа & 70 & 362 \\
\hline Программное обеспечение & 271 & \\
\hline
\end{tabular}

Источник: оставлена автором по данным Deloitte (2016)

Таблица 2. ТОП 10 компаний Technology Fast 500 тм EMEA Ranking 2016

\begin{tabular}{|l|l|c|l|}
\hline \multicolumn{1}{|c|}{ Компания } & \multicolumn{1}{|c|}{ Страна } & \multicolumn{1}{c|}{ Рост,\% } & \multicolumn{1}{c|}{ Сектор } \\
\hline Fingerprint Cards & Швеция & 28166 & Программное обеспечение \\
\hline Bilgikent & Турция & 16015 & Аппаратное обеспечение \\
\hline Codewise & Польша & 13052 & Программное обеспечение \\
\hline Auka & Норвегия & 11487 & Программное обеспечение \\
\hline Horizontal Software & Франция & 8339 & Программное обеспечение \\
\hline Brain Labs Digital & Великобритания & 8255 & Медиа \\
\hline Magisto & Израиль & 8119 & Медиа \\
\hline Chauffeur-Prive & Франция & 7020 & Программное обеспечение \\
\hline Wikifolio Financial Tесhnologies & Австрия & 16015 & Программное обеспечение \\
\hline GoCardless & Великобритания & 13052 & Программное обеспечение \\
\hline
\end{tabular}

Источник: составлена автором по данным Deloitte (2016) 
выручку в среднем на $347 \%$.

Меньше всего в рейтинге оказалось БРК сектора чистых технологий (20 компаний составили $4 \%$ общего числа участников). Средний рост их выручки составил 471\%. В Табл. 2 представлены данные о темпах роста компаний, вошедших в Топ 10 рейтинга.

Средний темп роста выручки всех компанийпобедителей рейтинга составил 967\%, диапазон роста отдельных компаний - $27914 \%$ (от $212 \%$ (французская компания Syntnes'3D) до 28126\% (шведская компания Fingerprint Cards) [55].Таким образом, все компании за 4 года как минимум удвоили выручку и тем самым продемонстрировали экспоненциальный рост. Большинство быстрорастущих высокотехнологичных компаний рейтинга отвечает критериям ЭксО и используют эту модель масштабирования бизнеса (Исмаил С. И др., 2017, Дзюбенко, 2018 а,).

Географическое распределение участников рейтинга.

В Топ-500 самых быстрорастущих высокотехнологичных компаний региона ЕБВА 2016 вошли страны Европы и Ближнего Востока, страны Африки не вошли в исследование. Региональная сструктура рейтинга представлена на Рис. 2.
Лидером по количеству компаний, представленных в рейтинге, стала Франция (94 компании). За ней следуют Великобритания (70), Нидерланды (54), Норвегия (50) и Швеция (50). На Рис. 3 показаны различия в присутствии самых высокотехнологичных БРК в странах региона.

Количество высокотехнологичных быстрорастущих компаний в странах сильно колеблется в пределах среднего показателя по выборке. Некоторые страны намного выше среднего показателя количества БРК по региону ЕБВА, а другие намного ниже. Высокотехнологичные БРК присутствуют во всей бизнес-экономике региона, хотя и с различной интенсивностью. Для оценки интенсивности присутствия высокотехнологичных БРК рассчитаны показатели концентрации (плотности) БРК в разных странах - количество БРК на млн. населения. Если обратиться к плотности высокотехнологичных БРК, то предыдущая картина существенно меняется - в странах, лидирующих по количеству БРК, их концентрация оказалась существенно ниже. Например, Франция занимает первое место по количеству БРК и девятое - по их концентрации, Исландия - на 17 месте по количеству БРК, но на втором по плотности БРК. Германия с ее развитой экономикой находится по этому
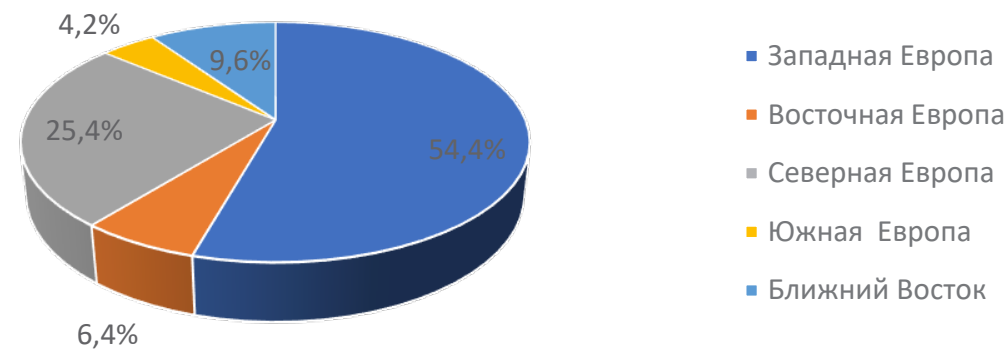

Puc. 2. Региональная стуктура Technology Fast 500 тм EMEA Ranking 2016 Источник: оставлен автором по данным Deloitte (2016)

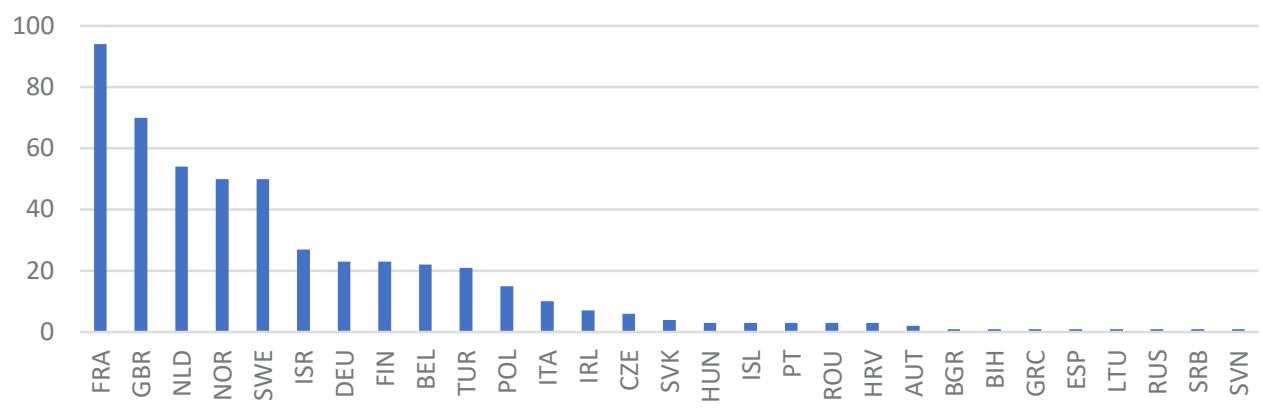

Puc. 3. Количество высокотехнологичных БРК в странах Источник: составлен автором по данным Deloitte (2016) 


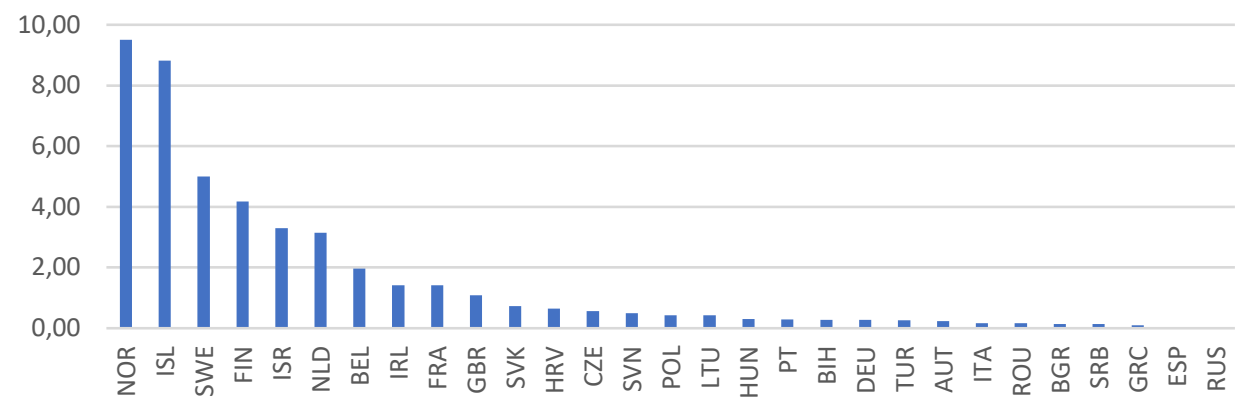

Рис. 4. Распределение стран по плотности высокотехнологичных БКР Источник: составлен автором по данным Deloitte (2016)

показателю на 19-м месте (Рис. 4). Наибольшая концентрация самых быстрорастущих высокотехнологичных компаний в Норвегии, Исландии, Финляндии, Швеции и Нидерландах.

Концентрация (плотность) БРК существенно (почти в 100) раз различается - от 9,5 в Норвегии до 0,1 в России и не засвистит от масштаба экономики. Большинство высокотехнологичных БРК концентрируются в странах с высоким уровнем экономического развития и географической концентрации. Успешные компании, имеющие годовой доход более 80 тыс. евро (условия участия в рейтинге), расположены в странах с наиболее благоприятными рамочными условиями, что подтверждает присутствие более $60 \%$ всего числа БРК в пяти экономически развитых странах-лидерах.

Взаимосвязь присутствия высокотехнологичных БРК и экономического развития страны.

Рост количества и развитие высокотехнологичных компаний, безусловно, является положительным фактором для экономики каждой страны. Вопрос в том, как, с одной стороны, экономическая среда способствует становлению и развитию этих компаний, с другой стороны существует ли взаимосвязь между количеством и высокими темпами роста высокотехнологичных компаний, богатством страны и уровнем благосостояния населения.

Корреляционный анализ показал, что в выборке в целом связь между количеством высокотехнологичных БРК и уровнем богатства страны (размером экономики), измеренным показателем ВВП (ППС)* умеренная (коэффициент кор- реляции равен 0,6$)$, а связь между количеством высокотехнологичных БРК и благосостоянием населения, измеренным ВВП (ППС) *** на душу населения, слабее (коэффициент корреляции $0,47)$. Уровень благосостояния населения по выборке в целом оказывает более существенное влияние на концентрацию высокотехнологичных БРК (коэффициент корреляции составил 0,75 ) (Рис 5 а). Теснота связи между концентрацией (плотностью) высокотехнологичных БРК и размером ВВП (ППС) слабая отрицательная (коэффициент корреляции равен - 0,11).

Однако, картина существенно различается по группам стран с разным уровнем экономического развития. Показатели корреляции между количеством высокотехнологичных БРК и размером экономики страны варьируются от 0,98 для экономически развитых стран с наибольшим числом БРК до 0.12 для стран с переходной экономикой, большинство которых представлены одной компанией. В группе экономически развитых стран с высокой концентрацией БРК их плотность коррелирует с уровнем благосостояния населения (коэффициент корреляции 0,78), а в странах, отстающих по уровню экономического развития, нет (значение коэффициента корреляции вдвое меньше) (Рис. 5 b).

Группы стран, отличающихся уровнем экономического развития, также неоднородны по анализируемой взаимосвязи. Например, в экономически развитых странах с относительно низкой концентрацией БРК связь между плотностью БРК и уровнем богатства страны и благосостояния населения слабая отрицательная (коэффициенты корреляции - 0,5 и - 0,3 соот-

\footnotetext{
* Рейтинг стран по объёму ВВП в 2019 году (МВФ; по паритету покупательной способности). Валовой внутренний продукт стран в 1980-2019 годах (МВФ; ППС, млрд. долл.). URL: https://svspb.net/danmark/vvp-stran.php

** Валовой внутренний продукт на душу населения в странах мира (МВФ; по паритету покупательной способности). Рейтинг стран по размеру ВВП на душу населения в 1980-2019 гг. (МВФ; ППС, долл.). URL: http://svspb. net/danmark/vvp-stran-na-dushu-naselenija.php
} 

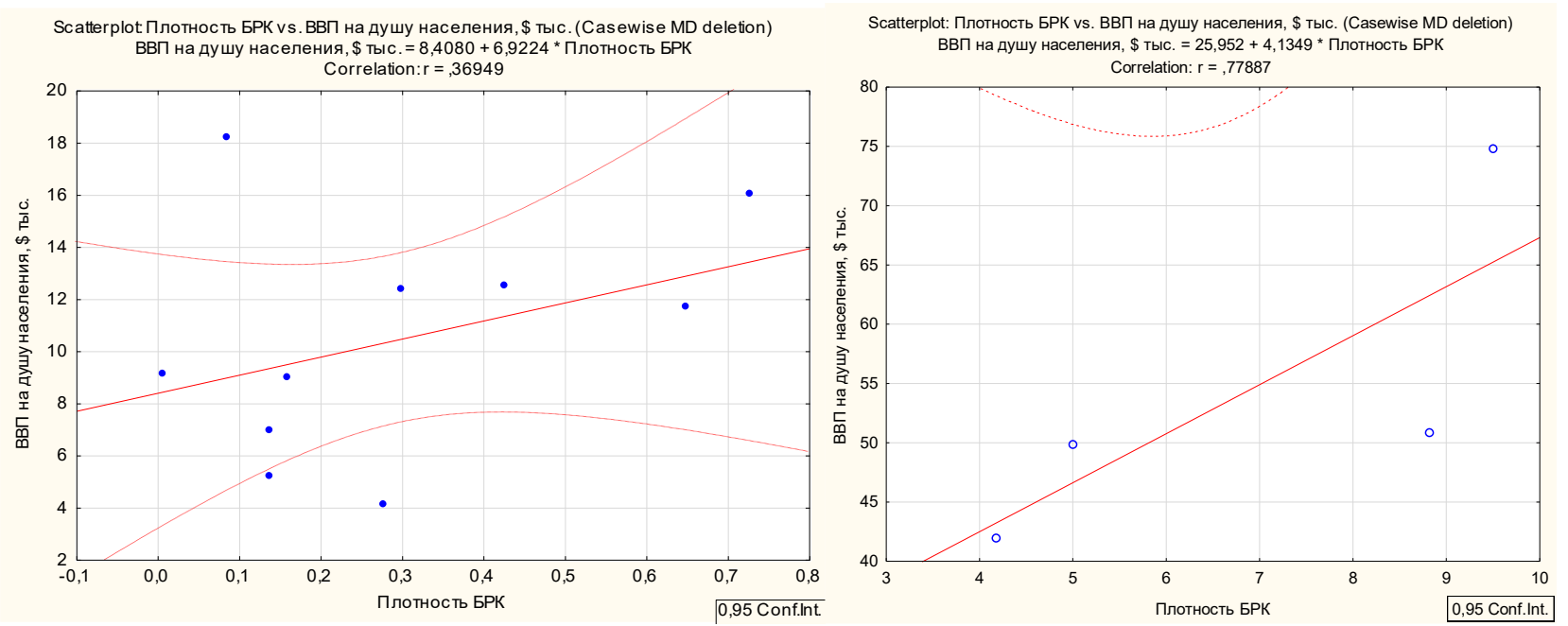

Puc. 5. Диаграмма рассеяния показателей плотности БРК и уровня благосостояния населения: а) вся выборка (слева), b) страны с переходной экономикой (справа) Источник: составлен автором по результатам анализа

ветственно). В целом в большинстве стран региона ЕБВА присутствие высокотехнологичных БРК не зависит от размера экономики и слабо коррелирует с уровнем благосостояния населения и определяется другими факторами, связанными с особенностями бизнес-среды каждой страны, технологической и предпринимательской экосистемой. Также оно может быть связано с эпизодическим и довольно неопределенным и непредсказуемым характером высокого роста компаний.

Далее было исследовано влияние на количество и концентрацию высокотехнологичных БРК внутренних расходов стран на НИОКР. Анализ показал отсутствие корреляции этих показателей (Рис. 6).

В странах с высокой концентрацией БРК показатели внутренних расходов на НИОКР,\% ВВП относительно низкие. И наоборот - в странах с относительно с высокими значениями показателей внутренних расходов на НИОКР,\% ВВП
(Польше, Венгрии Сербии, Румынии) концентрация высокотехнологичных БРК низкая. Таким образом, присутствие и концентрация высокотехнологичных БРК не зависит величины внутренних расходов страны на НИОКР.

В целом общая тенденция регионального развития высокотехнологичного бизнеса проявляется тем, что быстрорастущие высокотехнологичные компании все менее сосредоточены в традиционных ведущих экономиках стран Западной и Северной Европы и более равномерно распределяются по всему региону, включая Восточную и Южную Европу. Однако, стран и регионы существенно отличаются по присутствию и развитию высокотехнологичных БРК.

Взаимосвязь роста технологических БРК с уровнем и динамикой экономического развития страны.

Для межстранового сравнения динамики роста высокотехнологичных БРК были рассчита-

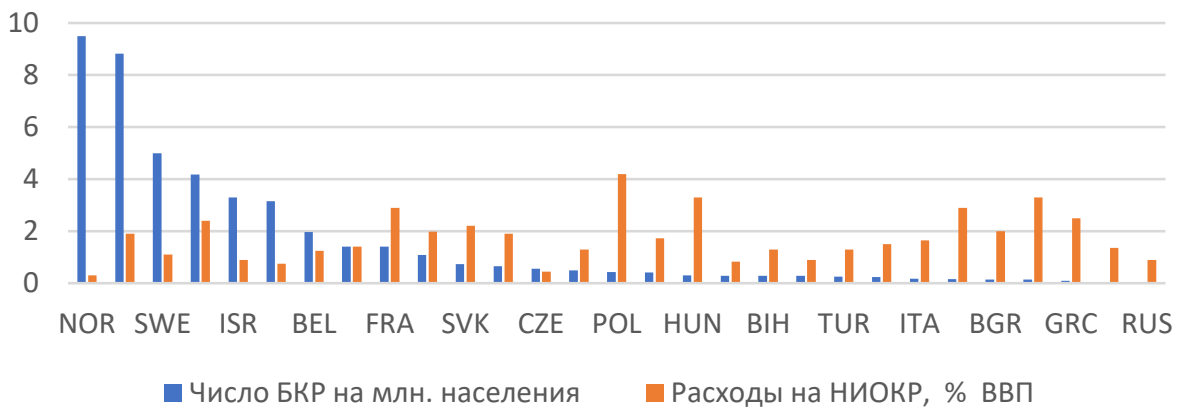

Puc. 6. Концентрация высокотехнологичных БРК и доля расходов на НИОКР в ВВП Источник: составлен автором по результатам расчетов 
ны средние по странам показатели совокупного роста выручки БРК (Табл. 3), а также значения среднего роста выручки БРК каждой страны по сравнению и Испанией (столбец 6).

Лидером по темпам роста являются высокотехнологичные БРК Австрии, их рост почти в 15 раз превысил показатели Испании. На втором месте Португалия, в которой высокотехнологичные БРК в среднем росли в 7,3 раза быстрее Испанских. Третье место с небольшим отрывом заняла Турция. Высокую позицию заняли также Греция и Босния и Герцеговина, представленные, однако, лишь одной компанией. Великобритания, Германия, Франция, Норвегия заняли средние позиции по темпам роста выручки
БРК. Такая ситуация объясняется большим числом компаний этих стран в составе участников рейтинга и широким диапазоном значений показателей роста их выручки. Таким образом, в странах региона отмечается не только неравномерное распределение, но и неравномерное развитие (рост) высокотехнологичных БРК.

Наши предыдущие исследования показали отсутствие взаимосвязи между темпами роста высокотехнологичных БРК и масштабом экономики, а также уровнем благосостояния населения. В странах с высоким уровнем благосостояния (за исключением Австрии) темпы роста высокотехнологичных БРК оказались ниже, чем в странах с относительно низким уровнем бла-

Таблица 3. Показатели динамики роста высокотехнологичных БРК

\begin{tabular}{|c|c|c|c|c|c|}
\hline \multirow{2}{*}{ Страна } & \multicolumn{5}{|c|}{ Рост выручки, \% } \\
\hline & Средний & Max & Min & Диапазон & Относительный \\
\hline 1 & 2 & 3 & 4 & 5 & 6 \\
\hline Австрия & 4135 & 7001 & 1270 & 5731 & 1493 \\
\hline Португалия & 2028 & 5541 & 236 & 5305 & 732 \\
\hline Турция & 2024 & 16015 & 235 & 15780 & 731 \\
\hline Греция & 1761 & 3129 & 214 & 2915 & 636 \\
\hline Босния и Герц. & 1760 & 1760 & 1760 & 0 & 635 \\
\hline Польша & 1724 & 11487 & 343 & 11144 & 622 \\
\hline Израиль & 1335 & 8119 & 216 & 7903 & 482 \\
\hline Сербия & 1109 & 1103 & 1103 & 0 & 400 \\
\hline Венгрия & 1071 & 1070 & 480 & 590 & 387 \\
\hline Великобритания & 1011 & 8255 & 213 & 8042 & 365 \\
\hline Словакия & 919 & 1965 & 380 & 1585 & 332 \\
\hline Германия & 874 & 6548 & 213 & 6335 & 316 \\
\hline Франция & 805 & 8339 & 212 & 8127 & 291 \\
\hline Норвегия & 797 & 11487 & 304 & 11183 & 288 \\
\hline Ирландия & 720 & 2596 & 232 & 2364 & 260 \\
\hline Россия & 691 & 691 & 691 & 0 & 249 \\
\hline Италия & 689 & 2068 & 229 & 1839 & 249 \\
\hline Швеция & 688 & 28126 & 258 & 27868 & 248 \\
\hline Финляндия & 603 & 3433 & 221 & 3212 & 218 \\
\hline Бельгия & 588 & 2294 & 214 & 2080 & 212 \\
\hline Нидерланды & 577 & 3676 & 214 & 3462 & 208 \\
\hline Болгария & 560 & 560 & 560 & 0 & 202 \\
\hline Хорватия & 535 & 702 & 527 & 175 & 193 \\
\hline Словения & 380 & 381 & 381 & 0 & 137 \\
\hline Исландия & 378 & 550 & 272 & 278 & 136 \\
\hline Румыния & 371 & 399 & 330 & 69 & 134 \\
\hline Литва & 367 & 367 & 367 & 0 & 132 \\
\hline Чехия & 347 & 347 & 347 & 0 & 125 \\
\hline Испания & 277 & 277 & 277 & 0 & 100 \\
\hline
\end{tabular}

Источник: составлена автором по результатам расчетов 
госостояния и наоборот (Дзюбенко, 2018 b). Сaмые низкие средние показатели роста выручки компаний оказались в странах с самым высоким уровнем ВВП на душу населения. С целью выявления причин такой взаимосвязи в анализ были включены показатели экономического роста стран рейтинга. По данным Всемирного банка* были рассчитаны средние за анализируемый период значения среднегодовых темпов роста ВВП (ППС) и ВВП (ППС) на душу населения. Страны ранжированы по уровню и динамике экономического развития, а также динамике роста высокотехнологичных БРК (Табл. 4).

Данные таблицы демонстрируют отсутствие прямой связи динамики роста высокотехнологичных БРК с уровнем и динамикой роста богатства страны и благосостояния населения, и это подтвердили результаты корреляционного анализа. По выборке в целом коэффициенты корреляции роста выручки компаний со среднегодовым темпом роста ВВП составил 0,06 , а со среднегодовым темпом роста ВВП на душу населения $-0,18$. Однако, картина неоднородна и неоднозначна. В странах-лидерах только по уровню ВВП (Италии, России, Турции) не отмечается высокий рост БРК. Высокотехнологичные компании лучше развиваются и растут в странах с высоким уровнем ВВП и благосостояния населения - Германии, Великобритании, Швеции. В отдельных странах быстро растут не только высокотехнологичные компании, но и богатство страны (Германия, Босния и Герцеговина) и благосостояние населения (Германия). Таким образом, скорость роста самых быстрорастущих технологических компаний одновременно явля- ется органическим следствием экономического развития страны и активно влияет на динамику экономического роста, но в большей степени определяется внутренними факторами компаний и развитием предпринимательских экосистем.

Взаимосвязь создания и развития высокотехнологичных БРК с предпринимательской экосистемой.

Для выявления факторов, объясняющих различную концентрацию и развитие высокотехнологичных БРК в разных странах, был проведен кластерный анализ. В анализе макроэкономической и институциональной среды использован широкий набор переменных, но ввиду ограниченности выборки в кластерный анализ ограничен десятью показателями. Выбраны наиболее сильно коррелированные детерминанты и\или охватывающие более широкую область: ВВП на душу населения, этика и коррупция, инфраструктура, степень ориентации на клиента, уровень технологического развития, географическая концентрация, доступность новейших технологий и венчурного капитала. Кластерный анализ проведен методом для k-средних с использованием программы Statistica. Преобразование переменных и кластеризация осуществлялось с помощью метода максимального расстояния. Результаты анализа приведены в Табл. 5.

Кластеры отличают разные позиции в отношении количества и плотности высокотехнологичных БРК, динамике их роста, институциональной среды и нормативного регулирования, инфраструктуры, эффективности рынка труда, финансового и товарного рынка, уровня и дина-

* Рейтинг стран по темпам роста ВВП. URL: https://nonews.co/directory/lists/countries/gdp-temp

Таблица 4. ТОП 10 стран Technology Fast 500 тм EMEA Ranking 2016

\begin{tabular}{|c|c|c|c|c|}
\hline \multirow[b]{2}{*}{ ВВП (ППС) } & \multirow{2}{*}{$\begin{array}{c}\text { ВВП на } \\
\text { душу населения }\end{array}$} & \multicolumn{3}{|c|}{ Среднегодовые темпы роста } \\
\hline & & Выручки компаний & ВВП (ППС) & $\begin{array}{c}\text { ВВП на душу насе- } \\
\text { ления }\end{array}$ \\
\hline Германия & Норвегия & Австрия & Испания & Германия \\
\hline Великобритания & Испания & Бельгия & Ирландия & Словакия \\
\hline Франция & Ирландия & Швеция & Польша & Норвегия \\
\hline Италия & Исландия & Великобритания & Босния и Герцог. & Испания \\
\hline Россия & Германия & Болгария & Румыния & Португалия \\
\hline Нидерланды & Швеция & Босния и Герцог. & Словакия & Исландия \\
\hline Турция & Австрия & Германия & Германия & Финляндия \\
\hline Швеция & Великобритания & Венгрия & Португалия & Венгрия \\
\hline Польша & Нидерланды & Израиль & Норвегия & Хорватия \\
\hline Австрия & Финляндия & Чехия & Бельгия & Ирландия \\
\hline
\end{tabular}

Источник: составлена автором по результатам расчетов 
Таблица 5. Результаты кластерного анализа

\begin{tabular}{|l|l|}
\hline Кластер 2 (7 стран) & Кластер 3 (4 страны) \\
\hline Испания & Исландия \\
Италия & Норвегия \\
Литва & Финляндия \\
Португалия & Швеция \\
Словения & \\
Турция & \\
Чехия & \\
\hline Кластер 4 (10 стран) & Кластер 1 (8 стран) \\
\hline Болгария & Австрия \\
Босния и Герцеговина & Бельгия \\
Венгрия & Великобритания \\
Греция & Германия \\
Польша & Израиль \\
Россия & Ирландия \\
Румыния & Нидерланды \\
Сербия & Франция \\
Словакия & \\
Хорватия & \\
\hline
\end{tabular}

Источник: составлена автором по результатам кластерного анализа

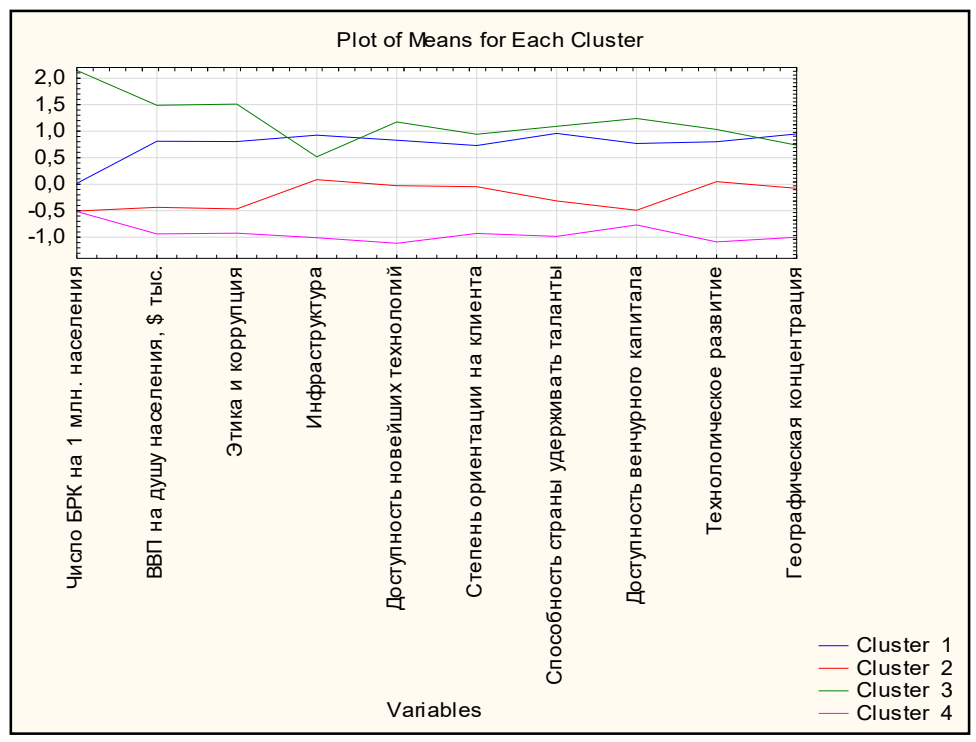

Puc. 7. Средние стандартизированные значения исследуемых показателей по кластерам Источник: составлен автором по результатам расчетов

мик технологического, инновационного и экономического развития вошедших в них стран. Кривые средних стандартизированных значений показателей, включенных в анализ, для каждого полученного кластера представлены на Рис. 7.

Кластеры 1 и 3 занимают близкие позиции, но уверенно лидирует Кластер 3, в который вошли страны Северной Европы с высоким уровнем экономического развития, благоприятной институциональной средой и наибольшей плотностью БРК. Кластер 1, объединивший высоко- развитые страны с наибольшим количеством и самыми высокими темпами роста БРК, несколько отстает от лидера по всем анализируемым показателям, кроме инфраструктуры и географической концентрации. Группу стран, вошедших в первый кластер, отличают самые высокие средние темпы экономического роста, самые низкие среднегодовые расходы на НИОКР и уровень инфляции. Кластеры 2 и 4 существенно отличаются от них по всем анализируемым показателям. В Кластере 2 значения всех анализируемых показателей ниже средних по 
выборке, намного ниже среднего значения показатели плотности БРК (в пять раз) и ВВП на душу населения (в полтора раза). В странах этого кластера самая низкая доля расходов на НИОКР в ВВП, самые низкие показатели благосостояния населения, самый высокий уровень инфляции. Вызывает озабоченность уровень коррупции и доступность венчурного капитала. Нижние позиции по всем показателям принадлежат кластеру 4, в котором вдвое ниже среднего по выборке величина ВВП, почти в три раза - уровень благосостояния населения, более, чем в 5 раз - количество и плотность БРК. Показатели данного кластера существенно отличаются от Кластера 3: в пять раз ниже уровень благосостояния населения, вдвое выше уровень коррупции, почти в 10 раз меньше среднее число БРК и более, чем в 23 раза ниже их концентрация.

Самые быстрорастущие технологические компании сосредоточены в странах с высоким уровнем благосостояния населения, технологического, инновационного и экономического развития, развитой инфраструктурой, в которых отсутствует коррупция, высок уровень доверия к правительству, доступны новейшие высокие технологии и венчурный капитал, созданы при- влекательные для условия талантов и развития предпринимательства.

Для верификации результатов кластерного анализа были рассчитаны средние значения индексов инновационного развития, конкурентоспособности, экономической свободы, человеческого развития (Табл. 6).

Самые высокие средние значения всех индексов в Кластере 3, Кластер 3 лишь незначительно отстает по некоторым показателям. Страны-лидеры по количеству самых быстрорастущих технологический компаний (Кластеры 1 и 3) отличает высокий уровень развития информационно-коммуникационных технологий, конкурентоспособности, инновационности, экономической свободы, процветания, человеческого развития и счастья. Страны-аутсайдеры, вошедшие в Кластеры 2 и 4, существенно отстают по всем показателям, самые низкие значения всех индексов в Кластере 4. Картина полностью совпадает с результатами кластерного анализа и наглядно демонстрирует, что различие в присутствии в странах высокотехнологичных БРК и динамике их роста объясняется условиями окружающей институциональной среды, характеристиками предпринимательских экосистем.

Таблица 6. Средние значения индексов

\begin{tabular}{|c|c|c|c|c|c|}
\hline Переменная & All Case & Cluster 1 & Cluster 2 & Cluster 3 & Cluster 4 \\
\hline Индекс развития ИКТ* & 7,5 & 8,2 & 7,1 & 8,4 & 6,8 \\
\hline Глобальный инновационный индекс & 48,1 & 56,5 & 45,5 & 57,8 & 39,2 \\
\hline Индекс экономической свободы & 67,7 & 72,0 & 66,0 & 74,3 & 62,8 \\
\hline $\begin{array}{l}\text { Индекс глобальной конкурентоспособно- } \\
\text { сти***** }\end{array}$ & 4,7 & 5,3 & 4,5 & 5,3 & 4,2 \\
\hline Индекс процветания ${ }^{* * * * * *}$ & 68,4 & 74,2 & 66,8 & 78,0 & 61,1 \\
\hline Индекс человеческого развития ${ }^{* * * * * * * *}$ & 0,9 & 0,9 & 0,9 & 0,9 & 0,8 \\
\hline Всемирный индекс счастья ${ }^{* * * * * * * * *}$ & 6,3 & 6,9 & 5,9 & 7,4 & 5,5 \\
\hline
\end{tabular}

Источник: составлена автором по результатам расчетов

* Рейтинг стран мира по уровню развития информационно-коммуникационных технологий. Индекс развития информационно-коммуникационных технологий. Гуманитарная энциклопедия: Исследования [Электронный ресурс]. Центр гуманитарных технологий, 2006-2021 URL: https://gtmarket.ru/ratings/ict-development-index

** CM. Dutta et al. (2016)

*** 60. The Heritage Foundation (2016) Рейтинг экономической свободы стран мира 2016 года. [Электронный ресурс]. Центр гуманитарных технологий, 2016. URL: https://gtmarket.ru/news/2016/02/01/7293

***** CM. Schwab (2016)

****** CM. Legatum Institute (2016)

******* Индекс человеческого развития (ИЧР) 2016. URL: https://nonews.co/directory/lists/countries/index-human ******* Рейтинг стран мира по уровню счастья 2016. URL: https://gtmarket.ru/ratings/happy-planet-index 
Заключение

Эмпирический анализ межстрановых и специфических для стран-участников рейтинга Technology Fast 500 тм EMEA Ranking показателей, имеющих отношение к БРК, проливает свет на условия, влияющие на их создание и развитие.

Анализ показал, что количество самых быстрорастущих технологических компаний в странах региона ЕБВА сильно колеблется в пределах среднего показателя по выборке и слабо коррелирует с размером национальных экономик и темпами экономического роста. Напротив, наблюдается связь между динамикой роста высокотехнологичных компаний и динамикой роста богатства страны, измеряемой темпами роста ВВП. Это свидетельствует о том, что скорость роста высоких технологий и компаний, с одной стороны, является органическим следствием экономического состояния региона, с другой стороны, активно влияет на экономические процессы.

Динамичный рост самых быстрорастущих технологических компаний достигается благодаря инновациям, экспоненциальным технологиям, созданию и развитию новейших отраслей экономики. Рост таких компаний является самостоятельным предпринимательством, которое может быть отражено во многих контекстах. Это было признано С. Марумом в его книге «Стартапы Черных лебедей: понимание подъема успешного технологического бизнеса в маловероятных местах» (Mahroum, 2016), название которой отражает определенный контекст роста компаний, отличный от современных стратегий роста.

Определенные природные и социально- экономические условия способствуют созданию технологических БРК, но размер экономики, уровень богатства страны внутренние затраты на НИОКР, динамика экономического развития страны не являются определяющими факторами присутствия и роста высокотехнологичных БРК.

Различие в присутствии в странах высокотехнологичных БРК и динамике их объясняется условиями макроэкономической и институциональной среды, характеристиками предпринимательской экосистемы. Наиболее важными детерминантами создания и развития самых быстрорастущих технологических компаний являются: уровень благосостояния населения, качество институтов, степень доверия к политикам, этика и коррупция, развитая инфраструктура, уровень технологического развития, способность стран удерживать таланты и возможность привлекать их со стороны, доступность новейших технологий и венчурного капитала.

Самых быстрорастущие технологические компании занимают исключительные позиции в экономике стран и регионов. Они играют важную роль в качестве динамического элемента экономики, степень влияния которого с одной стороны, соответствует экономическому состоянию окружающей среды и уровню экономического благосостояния с другой стороны, интенсивность их действия соответствует динамике роста экономики. Создание, присутствие и развитие таких компаний определяется рамочными условиями их функционирования, степенью развития и качеством предпринимательской экосистемы и, в свою очередь, оказывает на них активное влияние.

Источник финансирования: Статья подготовлена по плану НИР ИЭОПП СО РАН в рамках проекта XI.172.1.3 (№ АAAA-A17-117022250130-8) «Теория и методология стратегического управления развитием высокотехнологичного бизнеса как базиса новой индустриализации».

\section{Библиографический список}

1. Земцов С.П., Чернов А.В. (2019) Какие высокотехнологичные компании в России растут быстрее и почему. Журнал Новой экономической ассоциации, № 1 (41), C. 68-99 [Zemtsov, S.P., Chernov, A.V. (2019) Which hightech companies in Russia are growing faster and why. Journal of the New Economic Association, No. 1 (41), Pp. 68-99. (In Russian).]

2. Дзюбенко И.Б. (2018 а) Экспоненциальный рост высокотехнологичных компаний. Современные концепции науки будущего. Проблемы и перспективы инновационного развития современной экономики. Материалы международной научно-практической конференции. 2018. Издательство: Общество с ограниченной ответственностью «Центр профессионального менеджмента «Академия Бизнеса» (Саратов). С. 20-24. [Dzyubenko, I.B. (2018 a) Exponential growth of high-tech companies. Modern concepts of science of the future. Problems and prospects of innovative development of modern economy. Materials of the international scientific and practical conference. 2018. Publishing House: Limited Liability Company «Professional Management Center» Academy of Business «(Saratov). Pp. 20-24. (In Russian).] 
3. Дзюбенко И.Б. (2018 b) Быстрорастущие высокотехнологичные компании Европы, Ближнего Востока, Африки (ЕБВА): закономерности и факторы роста. Московский экономический журнал, № 5, С. $215-236$. [Dzyubenko, I.B. (2018 b) Fast-growing high-tech companies in Europe, the Middle East, Africa (EBWA): patterns and growth factors. Moscow Economic Journal. No. 5, Pp. 215-236 (In Russian).] DOI: 10.24411/2413-046X-201815113

4. Дзюбенко И.Б., Дзюбенко А. С. (2018) Новые модели высокотехнологичного бизнеса: экспоненциальные организации. Московский экономический журнал, No. 5. С. 188-211. [Dzyubenko, I.B., Dzyubenko, A.S. (2018) New models of high-tech business: exponential organizations. Moscow Economic Journal, No. 5. Pp. $188-211$. (In Russian).] https://doi.10.24411/2413-046X-2018-15042

5. Дзюбенко И.Б. (2020) Экспоненциальные технологии и организации как фактор роста высокотехнологичного бизнеса. Science and Technology Innovations: Сборник статей IV Международной научно-практической конференции. 2020. Под общей редакцией А.Б. Черемисина; Международный центр научного партнерства. Петрозаводск: Новая наука. ISBN 978-5-00174-019-3. С. 47-52. [Dzyubenko, I.B. (2020) Exponential technologies and organizations as a factor in the growth of high-tech business. Science and Technology Innovations: Collection of articles of the IV International Scientific and Practical Conference. 2020. Edited by A. B. Cheremisin; International Centre for Scientific Partnership. Petrozavodsk: New Science. ISBN 978-5-00174019-3. Pp. 47-52. (In Russian).]

6. Исмаил С., Мэлоун М., Юри ван Геест, Диамандис П. (2017) Взрывной рост. Почему экспоненциальные организации в десятки раз продуктивнее вашей (и что с этим делать). Москва: Альпина Паблишер. C. 393. [Ismail, S, Malone, M., Yuri van Geest, Diamandis, P. Exponential Organizations: Why New Organizations Are Ten Times Better, Faster, Cheaper Than Yours (and What To Do About It). Moscow: Alpina Pablisher P. 393. (In Russian).]

7. Маркова В.Д., Трапезников И.С. (2016). Современные формы партнерства в бизнесе. Мир экономики и управления, T. 16, № 4. С. 109-119. [Markova, V.D., Trapeznikov, I.S. (2016). Modern forms of partnership in business. World of Economics and Management, Vol. 16, No. 4, Pp. 109-119. (In Russian).]

8. Юсупова А.Т., Халимова С.Р. (2017) Характеристики, особенности развития, региональные и отраслевые детерминанты высокотехнологичного бизнеса в России. Вопросы экономики, № 12. С. 142-154.[Yusupova, A.T., Halimova, S.R. (2017) Characteristics, development features, regional and industry determinants of hightech business in Russia. Voprosy Ekonomiki, No. 12. Pp. 142-154. (In Russian).]

9. Achi, Z., Doman, A., Sibony, O., Sinha, J., Witt, S. (1995). The Paradox of Fast Growth Tigers. McKinsey Quarterly, No. 3. Pp. 9-13.

10. Ács, Z. (2015). High-impact firms: gazelles revisited. Chapters, in: Global Entrepreneurship, Institutions and Incentives, chapter 29.- Edward Elgar Publishing, Pp. 542-583

11. Acs, Z.J., Armington, C., Zhang T. (2007) The determinants of new firm survival across regional economies: The role of human capital stock and knowledge spillover. Papers in Regional Science, Vol. 86(3), Pp.367-391. https://doi. org/10.1111/j.1435-5957.2007.00129.x

12. Aldrich, H.E., Ruef, M. (2018) Unicorns, Gazelles, and Other Distractions on the Way to Understanding Real Entrepreneurship in America. Academy of Management Perspectives, Vol. 32, No. 4, P. 37. https://doi.org/10.5465/ amp.2017.0123

13. Almus, M. (2002) What characterizes a fast-growing firm? Applied Economics, Vol. 34, Issue 12, Pp. 497-1508. https://doi.org/10.1080/00036840110105010

14. Audretsch, D., Dohse, D. (2007) Location: A neglected Determinant of Firm Growth. Review of World Economics, Vol. 1 (143), Pp. 79-107

15. Autio, E., Hölzl, W. (2008) Addressing Challenges for High-Growth Companies: Summary and Conclusions of the Europe Innova. Europe INNOVA paper № 6, European Commission, Luxembourg. P. 23. https://doi. org/10.2769/21570

16. Autor, D, Dorn, D, Katz, LF, Patterson, C, Reenen, J.V. (2020) The Fall of the Labor Share and the Rise of Superstar Firms. Quarterly Journal of Economics [Internet], Vol. 135, Issue 2. Pp. 645-709. https://doi.org/10.1093/qje/ qjaa004

17. Ayyagari, M., Demirgüç-Kunt, A., Maksimovic, V. (2018) Who are America’s Star Firms? World Bank Policy Research Working Paper, No. 8534. P. 70.

18. Birch, D. (1979) The Job Generation Process. Massachusetts Institute of technology Program on Neighborhood and Regional change, Washington-Cambridge,. P. 302

19. Birch, D., Medoff, J. (1994).Gazelles in: L. C. Solomon and A. R. Levenson (eds.) Labor Markets Employment Policy, and Job Creation, Westview: Boulder, Co, Pp. 159-168 
20. Bosma, N., Stam, E. (2012) Local Policies for High-Employment Growth Enterprises. Report prepared for the OECD, DBA International Workshop on «High-growth firms: local policies local determinants». Copenhagen, Pp. 1-27.

21. Brown, R., Mawson, S., Mason C. (2017). Myth-busting and entrepreneurship policy: the case of high growth firms. Entrepreneurship and Regional Development, Vol. 29, Issue5-6, Pp. 1-30. https://doi.org/10.1080/08985626.2017 .1291762

22. Bruns, K., Bosma, N., Sanders, M., Schramm, M. (2017). Searching for the existence of entrepreneurial ecosystems: a regional cross-section growth regression approach. Small Business Economics, Vol. 49, Pp. 31-54

23. Coad, A., Daunfeldt, S., Hoelzly, W., Johansson, D., Nightingale, P. (2014) High-growth firms: introduction to the special section. Industrial and Corporate Change, Vol. 23 No. 1, Pp. 91-112

24. Coad, A., Srhoj, S. (2020). Catching Gazelles with a Lasso: Big data techniques for the prediction of high-growth firms. Small Business Economics Vol. Pp. 541-565. https://doi.org/10.1007/s11187-019-00203-3

25. Davidsson, P., Achtenhagen, L., Naldi, L. (2010). Small firm growth. Foundations and Trends ${ }^{\circledR}$ in Entrepreneurship, Vol. 6, No. 2, Pp. 69-166. https://doi.org/10.1561/0300000029

26. Daunfeldt, S. O., Elert, N., Johansson, D. The (2010). Economic Contribution of High-Growth Firms: Do Definitions Matter? Ratio Working Papers 151, The Ratio Institute.

27. Delmar, F., Davidsson, P., Gartner, W.B (2003) Arriving at the high-growth firm. Journal of Business Venturing, Vol.18 (2), Pp.:189-216. https://doi.org/10.1016/S0883-9026(02)00080-0

28. Deloitte (2016) Technology Fast $500^{\text {тм }}$ Meet the growth-makers. Annual ranking of the fastest-growing technology companies in Europe, Middle East and Africa (EMEA). URL: https://www2.deloitte.com/content/dam/Deloitte/ global/Documents/About-Deloitte/central-europe/Deloitte\%20Tech\%20Fast\%20500\%20EMEA\%202016\%20 Ranking.pdf

29. Duruflé, G., Hellmann, T., Wilson, K. (2018) From start-up to scale-up: Examining public policies for the financing of high- growth ventures. Financing of High-Growth, Vol. 5, Pp. 179-219. https://doi.org/10.1093/ oso/9780198815815.003.0011

30. Dutta, S., Lanvin, B., Wunsch-Vincent, S. (2016) The Global Innovation Index 2016. Winning with Global Innovation Cornell University, INSEAD, WIPO.. P. 451.

31. Coad, A., Daunfeld, S.-O., Hölz, W., Johansson, D., Nightingale, P. (2014). High-growth firms: introduction to the special section. Industrial and Corporate Change № 23, Pp. 91-112. https://doi.org/10.1093/icc/dtt052

32. Coad, A., Rao, R. (2008). Innovation and firm growth in high-tech sectors: A quantile regression approach. Research Policy, Vol. 37, No. 4, Pp. 633-648. https://doi.org/10.1016/j.respol.2008.01.003

33. Henrekson, M., Johansson, D. (2010) Gazelles as job creators: A survey and interpretation of the evidence. Small Business Economics, Vol.35, Pp. 227-244. https://doi.org/10.1007/s11187-009-9172-z

34. European Commission(2013).Innovation Union Competitiveness report,Innovation.https://doi.org/10.2777/87066

35. European Commission (2019). European Innovation Scoreboard 2019 Methodology Report, European Innovation Scoreboard 2019. Brussels, Belgium. Ferrando, A., Pal, R., Durante, E. (2019) Financing and obstacles for high growth enterprises: the European case, EIB, Economics. EIB Working Papers, No. 3. Pp. 1-34.

36. Ferrantino, M. J., Mukim, M., Pearson, A., Snow, N. (2012) Gazelles and Gazillas in China and India. Electronic Journal, P.43. https://dx.doi.org/10.2139/ssrn.2167303

37. Geroski, P.A., Mata, J., Portugal, P. (2010) Founding conditions and the survival of new firms. Strategic Management Journal, Vol. 31, Issue 5, Pp. 510-529. https://doi.org/10.1002/smj.823

38. Harabi, N. (2005) Determinants of Firm Growth: An Empirical Analysis from Morocco. Munich Personal RePEc Archive, P. 30. URL: https://mpra.ub.uni-muenchen.de/4394/1/MPRA_paper_4394.pdf

39. Halla, I., Harasztosi, P. (2019). Job Creation in Europe: A firm-level analysis. Publications Office of the European Union, Luxembourg. https://doi.org/10.2760/590043

40. Hölzl W. (2009) Is the R\&D behaviour of fast-growing SMEs different? Evidence from CIS III data for 16 countries. Small Business Economics, Vol. 33 (1), Pp. 59-75. https://doi.org/10.1007/s11187-009-9182-x

41. Lee A. (2013) Welcome to the Unicorn Club: Learning From Billion-Dollar Start-ups. 2013. URL: http://techcrunch. com/2013/11/02/welcome-to-the-unicorn-club/

42. Li S. (2005) High tech spatial concentration human capital, agglomeration economies, location theories and creative cities. - $\backslash \backslash$ Electronic Theses and Dissertations. Paper 824. Louisville: University of Louisville. https://doi. org/10.18297/etd/824

43. Lia, M., Goetzb, S., Partridgec, M., Fleming, D. (2016) Location.Determinants of High-Growth Firms. Entrepreneurship \& Regional Development, Vol. 28, Issue 1-2. Pp. 97-125. https://doi.org/10.1080/08985626.2015.1109003

44. Lopez-Garcia, P., Puente, S. (2012) What makes a high-growth firm? A dynamic probit analysis using Spanish firmlevel data. Small Business Economics, No. 39, Pp. 1029-1041. https://doi.org/10.1007/s11187-011-9321-z 
45. Mahroum, S. (2016). Black Swan Start-ups: Understanding the Rise of Successful Technology. Luxembourg: P. 277

46. Mason, C.M. Productivity and the UK's (2020) Deficiency in Scale-ups. - Evidence Review. P. 21. URL: https:// productivityinsightsnetwork.co.uk/

47. Mason, C. M., Brown, R. (2013). Creating good public policy to support high-growth firms. Small Business Economics, No. 40, Pp. 211-225. https://doi.org/10.1007/s11187-011-9369-9

48. Mason, C.M., Harrison, R.T. (2006) After the exit: Acquisitions, entrepreneurial recycling and regional economic development. Regional Studies, Vol. 40, Issue 1, Pp. 55-73. https://doi.org/10.1080/00343400500450059

49. Monteiro, G. F. A. (2019) High-growth firms and scale-ups: a review and research agenda. Management Journal, Vol. 54, Issue 1, Pp. 96-111. https://doi.org/10.1108/RAUSP-03-2018-0004

50. OECD (2008) Measuring Entrepreneurship: A Digest of Indicators, OECD-Eurostat Entrepreneurship Indicators Program. P. 20. URL: https://www.hermes-osr.eu/attachments/230_oecd-indicators-report.pdf

51. Owen G. (2004) Where are the big gorillas? High technology entrepreneurship in the UK and the role of public policy.Entrepreneurship and Public Policy Project - Diebold Institute for Public Policy Studies: London, P. 29

52. Schreye P. (2000) High-growth firms and employment. OECD STI Working Paper Series. 2000/03. P. 49. https://doi. org/10.1787/861275538813

53. Schwab, K. (2016) The Global Competitiveness Report 2015-2016. World Economic Forum P. 403 URL: http:// www3.weforum.org/docs/gcr/2015-2016/Global_Competitiveness_Report_2015-2016.pdf

54. Simon, J. P. (2016) How to Catch a Unicorn. An exploration of the universe of tech companies with high market capitalization. Institute for Prospective Technological Studies. JRC Technical Report. EUR27822 EN. P. 85. https:// doi.org/10.2791/893975

55. Sloan M. (2020) What Is Hypergrowth? (And How Do You Achieve It?). URL:: https://www.drift.com/blog/what-ishypergrowth/

56. Stam, E., Spige, l B.(2016). Entrepreneurial Ecosystem. Discussion Paper Series, No. 16-13, P. 18.

57. Teruel-Carrizosa, M., De Wit, G. (2011) Determinants of high-growth firms: why do some countries have more highgrowth firms than others? Working Papers 2072/179670, Universitat Rovira i Virgili, Department of Economics.

58. Johnson J., Baldwin J. (1997). Successful entrants: creating the capacity for survival and growth. Canada, MicroEconomic Analysis Division, Ottawa: Statistics C.H. P. 11 